\title{
The Physicochemical Features of Binary Immiscible Metal Systems in a New Method of Synthesis and Crystallization
}

\author{
V. N. Gurin ${ }^{a}$, Yu. Grin'b ${ }^{,}$U. Burkkhardt ${ }^{b}$, and M. V. Konovalov ${ }^{a}$ \\ ${ }^{a}$ Ioffe Physicotechnical Institute, Russian Academy of Sciences, St. Petersburg, 194021 Russia \\ e-mail: vladimir.qurin@mail.ioffe.ru \\ ${ }^{b}$ Max Planck Institute of Chemical Solid-State Physics, Dresden, Germany
}

\begin{abstract}
Features of the structure of phase diagrams of immiscible binary metal systems for synthesis and crystallization of various compounds by a new method are considered: temperature and concentration limits of immiscibility, ratio of densities of system components, use of mixed solvents, and processes of hardening of pure immiscible systems. An example of obtaining crystals of refractory compounds is given.
\end{abstract}

DOI: $10.3103 / \mathrm{S} 1062873809100190$

\section{INTRODUCTION}

Earlier, information was reported about development of a new method of technology and research of interaction of elements in immiscible binary metal systems (immiscibility gap method) [1-3]. Unlike the usual solution-melt method [4], where one dissolvent $L$ is used (flax method), in the new method, synthesis and crystallization of the compound occur at the immiscibility boundary of two solvents $\left(L_{1}+L_{2}\right)$ [1-3]. In the short form, the key conditions of the new method consist in the following.

1. $\rho_{L 1}<\rho_{A}<\rho_{L 2} ; \rho_{L 2}>\rho_{B}>\rho_{L 1}$, where $\rho$ are the densities of initial reacting components $A$ and $B$ and two solvents. This relation of densities means that initial component $A$ must be dissolved and go down in the layer $L_{1}$, but must be lighter than the lower layer $L_{2}$, and other initial component $B$ must be dissolved and come to the surface in the layer $L_{2}$, but must be heavier than the upper layer $L_{1}$ accordingly.

2. The availability of wide temperature (several hundred degrees) and concentration (in almost the entire concentration range) immiscibility limits $\Delta T$ and $\Delta C$ in the system for synthesis of compounds and their crystal growth is necessary.

3. The existence of solubility of at least one of the initial reacting components $A$ (or $B$ ) in their layers or of their reaction products $A L_{1}\left(B L_{2}\right)$ with the element of the layer is necessary.

4. $\Delta F_{A B}<\Delta F_{A L 1}\left(A L_{2}, B L_{2}, B L_{1}, L_{1} L_{2}\right.$, etc. $) . \Delta F$ is the free energy of formation, and it should be the smallest for the synthesized compound.

Diagrams of processes that take place in immiscible systems are shown in Fig. 1. In this paper, the authors pay attention to some characteristic properties and differences of phase diagrams of such systems [5-7]. Production of both pure ingots and ingots with reacting components of immiscible systems, preparation and examination of metallographic sections, and extraction of synthesis products from a solvent metal matrix are carried out in the same way as in [2, 3]. Systems $\mathrm{Ga} / \mathrm{Pb}$ and $\mathrm{Al}+\mathrm{Ga} / \mathrm{Pb}$ are exceptions. In these systems, various refrigeration methods of an ingot are used during grinding and polishing in connection with the low melting temperature of $\mathrm{Ga}\left(29.77^{\circ} \mathrm{C}\right)$.

Only three systems $(\mathrm{Al} / \mathrm{Pb}, \mathrm{Al} / \mathrm{Cd}$, and $\mathrm{Pb} / \mathrm{Zn})$ have wide temperature and concentration immiscibility ranges (Table 1) [6, 7] of five metal systems that are the most suitable for experiments in standard conditions. Systems $\mathrm{Cd} / \mathrm{Ga}$ and $\mathrm{Ga} / \mathrm{Pb}$ are practically useless for technology because of small values $\Delta T$ and $\Delta C$ or low separation temperatures.

Generic aspects of the new method concern the boundary temperature and concentration immiscibility conditions of melts of elements, the presence of an immiscibility region bounded by a binodal, and the relation of densities of initial reacting components,

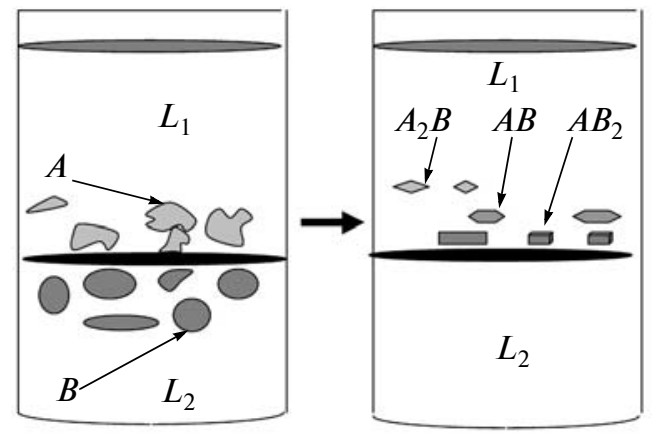

Fig. 1. Diagram of synthesis and crystallization in immiscible systems by the new method. The accumulation of initial reacting components on either side near immiscibility boundary and location of synthesis products in upper layer of immiscible systems (according to condition (1), see text) is displayed. 
Temperature and concentration immiscibility limits in some binary metal systems suitable for technology by the new method

\begin{tabular}{c|c|c|c|c|c|c}
\hline \multirow{2}{*}{$\begin{array}{c}\text { Binary } \\
\text { immiscible } \\
\text { system [7] }\end{array}$} & $T_{C}$ & $T_{\text {monotec }}$ & $\Delta T$ & $C_{\text {monotec }}$ & $C_{\text {transition point }}$ & $|\Delta C|$ \\
\cline { 2 - 7 } & \multicolumn{5}{|c}{ at \% } \\
\hline $\mathrm{Al} / \mathrm{Cd}$ & 1020 & 650 & 370 & 94.9 & 1.76 & $93.14(\mathrm{Cd})$ \\
$\mathrm{Al} / \mathrm{Pb}$ & 1566 & 659 & 907 & 97.91 & 0.19 & $97.71(\mathrm{~Pb})$ \\
$\mathrm{Zn} / \mathrm{Pb}$ & 798 & 417.8 & 380.2 & 94 & 0.3 & $93.7(\mathrm{~Pb})$ \\
\hline
\end{tabular}

Note: In [7], data on the phase diagram of the $\mathrm{Al} / \mathrm{Cd}$ system are incomplete and erroneous, because the binodal critical point $T_{C}=1020^{\circ} \mathrm{C}$ and the boiling point for $\mathrm{Cd} T_{\text {boil }}=770^{\circ} \mathrm{C}$, which is impossible without the presence of high pressure, whose value is not given. The region gas + fluid $(G+F)$ is not indicated on the diagram either, which causes difficulties regarding the possibility of heating the immiscible system to $1020^{\circ} \mathrm{C}$ without aggregative transmutations.

utilization of mixed solvents, and existence of an immiscibility boundary.

The purpose of this paper is a brief exposition of the essence of the new method, production of ingots and preparation of polished sections in immiscible systems, and realization of synthesis and crystallization of high-melting compounds in them.

\section{TEMPERATURE AND CONCENTRATION BOUNDARY CONDITIONS AND IMMISCIBILITY FIELD}

One can explain the special features of these conditions analyzing the structure of binary phase diagrams with an immiscibility field [5-8]. In such systems, initial reagents can be dissolved in both layers and generate the required connections, interacting on the immiscibility boundary. Interaction proceeds thanks to interdiffusion and convection of the initial particles of the compounds dissolving in both layers.

The diagram of a binary immiscible system is shown in Fig. 2. As follows from this figure, the immiscibility field is restricted to a dome-shaped curve called a binodal and its basal part contained by a monotectic and an inflection point or by two inflection points [5]. The peak temperature of immiscibility corresponds to a critical point $T_{C}$. Limits of temperature and concentration immiscibility fields $\Delta T$ and $\Delta C$ have the greatest meaning for production of compounds and their crystals in such systems. The greater the sizes they have, the more possibilities for synthesis and crystallization of compounds at various temperatures and conditions, and ratios of solvents and quantities of reacting substances dissolved in them. Possible types of phase diagrams with immiscibility field are given in [5] (it is necessary to note that, in the majority of reference media, points of monotectic, inflection, and eutectic are not given in such phase diagrams because of the small absolute values and lack of space in a figure [6-8]). It is possible to distinguish two types of immiscibility systems from [5]: (1) system with a monotectic and inflection point and (2) system with two inflection points. Existence of immiscibility sys- tems with two monotectics is impossible in connection with nonfulfillment of phase rules in this case.

After selection of the phase diagram with a suitable immiscibility field, the most difficult problem is (in accordance with the conditions of the method, see condition (1)) matching the required ratio of densities of all subsystems [3]. This ensures that the chemical reaction of initial compounds proceeds in conditions of cross interdiffusion and convection.

\section{EXPERIMENT}

\section{Boundary Surface in Immiscible Systems of Metals}

It is necessary to know how the boundary surface will appear in polished sections when performing synthesis and crystallization of compounds by the new method to solve the problem of an optimal way of extracting synthesis products from a metal matrix, and also for analyzing these products. Systems $\mathrm{Al} / \mathrm{Pb}$, $\mathrm{Zn} / \mathrm{Pb}$, and $\mathrm{Ga} / \mathrm{Pb}$ have been analyzed upon heating, respectively, to 800,800 , and $590^{\circ} \mathrm{C}$, soaking for $40-$ $60 \mathrm{~min}$ at the peak temperature, and cooling at rates of $3-5 \mathrm{~K} / \mathrm{h}$. The general view and boundary surfaces in polished sections of these systems are presented in Fig. $3(1-3)$. The shape of such borders in the solid

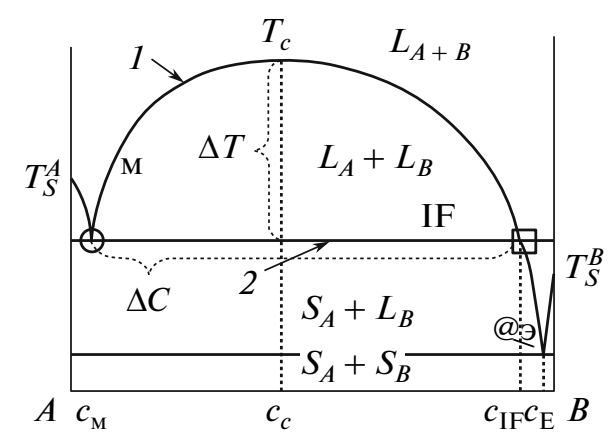

Fig. 2. Outline of the phase diagram with immiscibility field: (1) binodal curve, (2) binodal basal part where monotectic point is marked by circle, and inflection point is marked by square. The critical point $T_{C}$ on bimodal is marked above which there is a complete mixing of liquid components in appropriate proportions. 


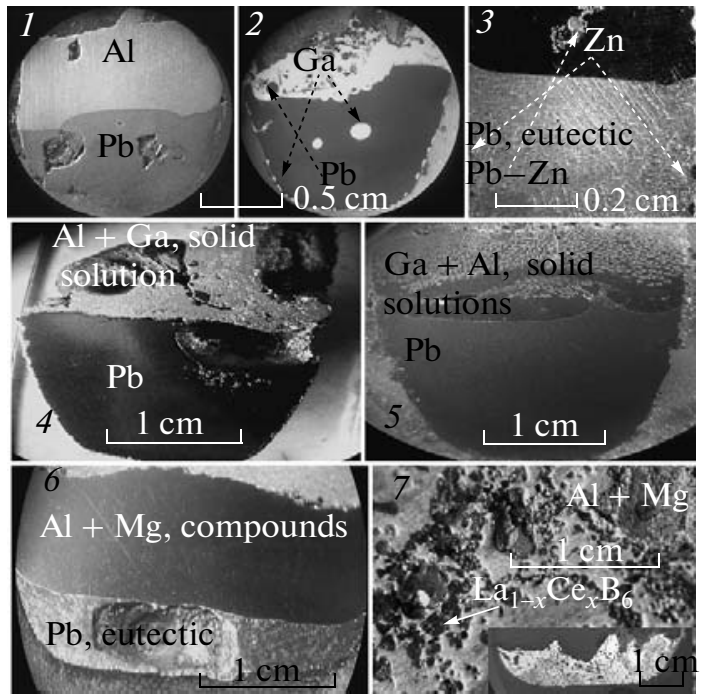

Fig. 3. Overall view of polished sections of binary and triple systems with an immiscibility: (1) $\mathrm{Al} / \mathrm{Pb}$ system with contraction cavities in $\mathrm{Al}$ and $\mathrm{Pb}$; (2) $\mathrm{Ga} / \mathrm{Pb}$ system; arrows indicate inclusions of one layer in the other both inside and on ingot perimeter; (3) $\mathrm{Zn} / \mathrm{Pb}$ system; eutectic is visible in layer of $\mathrm{Pb}$; (4) "ideal" system $\mathrm{Al}+\mathrm{Ga} / \mathrm{Pb}$ with $\mathrm{Al}$ excess $(\mathrm{Al}: \mathrm{Ga}=80: 20$, at \%); inclusions of one layer in the other are visible; layer of $\mathrm{Al}$ maintains granules of solid solutions of $\mathrm{Al}+\mathrm{Ga} ;(5)$ the same system as in 4 , but with $\mathrm{Ga}$ excess ( $\mathrm{Ga}: \mathrm{Al}=80: 20$, at \%); extraction of solid solutions of $\mathrm{Ga}+\mathrm{Al}$ are visible in layer of $\mathrm{Ga} ;(6) \mathrm{Al}+\mathrm{Mg} / \mathrm{Pb}$ system with compounds between $\mathrm{Al}$ and $\mathrm{Mg}$ in $(\mathrm{Al}+\mathrm{Mg})$ layer and eutectic in $\mathrm{Pb}$ layer in which a larger contraction cavity is located; (7) the same system as in 6 with isomeric crystals of solid solution of hexaborides of $\mathrm{La}$ and $\mathrm{Ce}: \mathrm{La}_{1-x} \mathrm{Ce}_{x} \mathrm{~B}_{6}$ (where $x \approx 0.05$ ) obtained in it

state depends on various reasons: the taken ratio of components, cooling rate, difference of melting temperatures of upper and lower metal, viscosities of layers, sizes of contraction cavity, etc. One can see the significant contraction cavities in the layer of $\mathrm{Pb}$ (system $\mathrm{Al} / \mathrm{Pb}$ ) and ones smaller in size in systems $\mathrm{Pb} / \mathrm{Zn}$ and $\mathrm{Ga} / \mathrm{Pb}(2,3)$ from Fig.3 $(1,4)$. The existence of mutual inclusions, as a rule, oval in the bulk, on the boundary surfaces is significant and on surface of ingots of both layers is significant.

This is due to the reasons mentioned above, including the flow of more low-melting metal of the upper layer between the solidified lower layer and a bowl (Fig. 3 (2), system $\mathrm{Ga} / \mathrm{Pb}$ ). A distinguished boundary surface between the two metals above which, according to condition (1) of the new method, synthesis and crystallization products should be located are visible in all systems (because component $B$ floating up in the lower layer to the immiscibility boundary must be heavier than the upper layer according to the condition, but after interacting on this boundary with component $A$ from the upper layer produces compound $A_{X} B_{y}$, which will be lighter than pure component $B$ and should transfer to the upper layer in connection with the reduction of density).
A so-called ideal triple system $\mathrm{Al}+\mathrm{Ga} / \mathrm{Pb}$ in which $\mathrm{Al}$ and $\mathrm{Ga}$ are mutually soluble in almost the entire interval of concentrations and both delaminate with $\mathrm{Pb}$, forming wide $\Delta T$ and $\Delta C$, is rather interesting. Experiments with excess $\mathrm{Al}(\mathrm{Al}: \mathrm{Ga}=80: 20$, at \%) and $\mathrm{Ga}(\mathrm{Ga}: \mathrm{Al}=80: 20$, at \%) upon heating $(3 \mathrm{~h})$ to $1000^{\circ} \mathrm{C}$, soaking for $60 \mathrm{~min}$, and cooling at a rate of $1.9 \mathrm{~K} / \mathrm{min}$ were performed. Correct boundary surfaces are formed in both cases, as follows from Fig. $3(4,5)$, and in the upper layer, granules of solid solutions $x \mathrm{Al}$. $y \mathrm{Ga}$ and $x \mathrm{Ga} \cdot y \mathrm{Al}$ are visible. Good mutual solubility of $\mathrm{Al}$ and $\mathrm{Ga}$ allows one to change the density of the upper layer, increasing it in $\mathrm{Al}$ excess and decreasing in $\mathrm{Ga}$ excess. Utilization of mixed solvents in one of the layers for synthesis of compounds by the new method is applied by the authors for the first time [3].

\section{Utilization of Mixed Solvents}

In synthesis of high-melting compounds, in particular, metals borides (and also carbides and silicides) by the new method, the main complication consists in selection of the solvent for a light nonmetal, for example, boron ( $\rho=2.34 \mathrm{~g} / \mathrm{m}^{3}$; hereinafter, $\rho$ is omitted). Low-melting metals are the most reasonable for synthesis: $\mathrm{Al}$ (2.70), $\mathrm{Zn}$ (7.14), $\mathrm{Cd}$ (8.64) are heavier than boron. In AlB is slightly soluble (and produces compounds), and in $\mathrm{Zn}$ and $\mathrm{Cd}$ melts, it is practically insoluble. Synthesis is attained by means of prolonged heating and soaking of the system in the usual solution-melt method. During the prolonged heating and soaking, boron is dissolved, distributed by volume of $\mathrm{Al}$ solvent through thermal diffusion and convection flows, and interacts in the bulk with another reaction component, for example, with a transition metal which is also distributed by volume of solvent. It is necessary that boron be dissolved and go down in its layer and another initial compound, for example, a rare-earth metal (REM), be dissolved and come to the surface in its layer to achieve interdiffusion and convection in the new method. Synthesis of compounds in this case proceeds on the immiscibility boundary, to which boron and REM move from either side. The solvent for boron can be extracted by mixing a light metal, for example, $\mathrm{Mg}$ (1.74), with a heavier metal, for example, $\mathrm{Al}(2.70)$, in the system $\mathrm{Al} / \mathrm{Pb}$, by choosing such a ratio of them which in density will be less than the density of boron (2.34) and will still maintain the immiscibility process. The obtained mixed solvent $(\mathrm{Al}+\mathrm{Mg})$ with a density of, for example, 2.2 like $\mathrm{Al}$ forms an immiscible system with $\mathrm{Pb}$ because of $\mathrm{Al}$ excess. There are intermetallic semiconductors between $\mathrm{Al}$ and $\mathrm{Mg}$ and between $\mathrm{Mg}$ and $\mathrm{Pb}$ in this system. But they are much less stable (their melting temperature $T_{\text {пл }}=550^{\circ} \mathrm{C}$ ) than, for example, synthesized hexaborides of REM $\left(T_{\text {melt }}=\sim 2300-2500^{\circ} \mathrm{C}\right)$.

The possibility of boundary surface production in ingots in the system $\mathrm{Al}+\mathrm{Mg}(\mathrm{Mg}: \mathrm{Al}=7: 10 \mathrm{wt} \%) / \mathrm{Pb}$ 


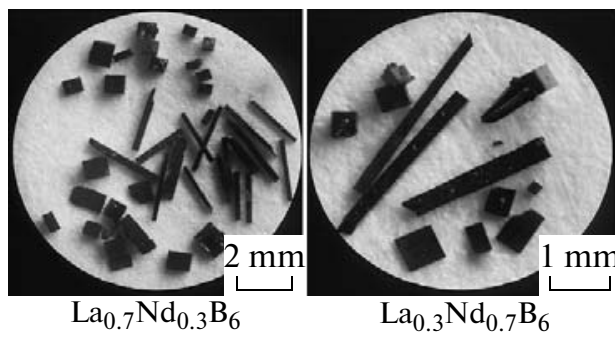

Fig. 4. Needle, lamellar, and isomeric crystals of solid solutions of high-melting hexaborides of $\mathrm{La}$ and $\mathrm{Nd}$ obtained in system with mixed solvent $(\mathrm{Al}+\mathrm{Mg},+\mathrm{B}) / \mathrm{Pb}(+\mathrm{La},+\mathrm{Nd})$ (analogous to the system presented in Fig. 3 (7)).

was investigated. The system was heated up to $850^{\circ} \mathrm{C}$ $(2 \mathrm{~h})$, soaked for $60 \mathrm{~min}$, and chilled at a cooling rate of $1.5 \mathrm{~K} / \mathrm{min}$. Production of solid solutions of hexaborides of $\mathrm{La}$ and $\mathrm{Ce}$ experiments in the system $\mathrm{Al}$ $(+\mathrm{Mg},+\mathrm{B}) / \mathrm{Pb}(+\mathrm{La},+\mathrm{Ce})$ was made at higher temperatures: heating $(4 \mathrm{~h})$ to $1300^{\circ} \mathrm{C}$, soaking for $4 \mathrm{~h}$, and chilling at a cooling rate of $39 \mathrm{~K} / \mathrm{h}$. These systems in a solidified state without initial components $(6)$ and with synthesis products, $\mathrm{La}_{1-x} \mathrm{Ce}_{x} \mathrm{~B}_{6}, x \approx 0.05$ (7), are presented in Fig. $3(6,7)$. One can clearly distinguish the boundary surface between $\mathrm{Al}$ and $\mathrm{Pb}$ layers, which contain a significant amount of taken $\mathrm{Mg}$ in picture (6). The presence of $\mathrm{Mg}$ in the upper layer of Al led to formation of unfaceted granules. Judging by the nonuniform, spotty surface of the Al layer (according to the phase diagram [7]), it is most likely that an interphase eutectic between $\beta\left(\mathrm{Al}_{3} \mathrm{Mg}_{2}\right)$ and $\gamma\left(\mathrm{Al}_{12} \mathrm{Mg}_{17}\right)$ is formed. The formation of compounds $\mathrm{Mg}_{2} \mathrm{~Pb}$ and eutectics between $\mathrm{Mg}_{2} \mathrm{~Pb}$ and $\mathrm{Pb}(\sim 83$ at \% according to [7]) is possible in the lower layer of $\mathrm{Pb}$.

The polished section (Fig. 3 (7)) was prepared only from the upper part of the ingot $(\mathrm{Al}+\mathrm{Mg}+$ hexaboride) in the experiment with reacting components from the obtained ingot because the whole ingot had large voids (cavities) separating the upper part from the lower part (containing $\mathrm{Pb}$ ) and the lower part was pulled off when cut (Fig. 3 (7), interpolation). On the polished section, one can clearly see extraction of crystals of a solid solution of hexaborides of La and $\mathrm{Ce}$, $\mathrm{La}_{1-x} \mathrm{Ce}_{x} \mathrm{~B}_{6}, x \approx 0.05$ (having a characteristic crimson color, like pure $\mathrm{LaB}_{6}$ ), located mainly at the bottom of the upper part, which corresponds to this method's synthesis requirements. Apparently, the existence of the possibility of formation of $\mathrm{Al}$ and $\mathrm{Mg}$ borides in the system does not prevent formation of more high-melting solid solutions of hexaborides of REM since the latter are more stable (see above, condition 4).

Synthesis (heating to $1360^{\circ} \mathrm{C}$, soaking for $6 \mathrm{~h}$, and chilling at a cooling rate of $175 \mathrm{~K} / \mathrm{h}$ ) of solid solutions of hexaborides of $\mathrm{La} \mathrm{(6.7)} \mathrm{and} \mathrm{Ce} \mathrm{(6.78)} \mathrm{and} \mathrm{La} \mathrm{and}$ $\mathrm{Nd}$ (7.00) was performed earlier [3] in the system $\mathrm{Al}$ $(+\mathrm{Mg},+\mathrm{B}) / \mathrm{Pb}(+\mathrm{La},+\mathrm{Nd})$. Meanwhile, the boron "sank" in compound $\mathrm{Al}+\mathrm{Mg}$ and went down to the boundary surface, and $\mathrm{La}$ and $\mathrm{Nd}$ "rose" to this boundary surface in the layer of $\mathrm{Pb}$ (11.4). From the upper layer $(\mathrm{Al}+\mathrm{Mg}+$ hexaboride) with dissolution in $\mathrm{HCl}(1: 2$ to $1: 4)$, crystals of solid solutions of hexaborides $\left(\mathrm{La}_{0.75} \mathrm{Nd}_{0.25} \mathrm{~B}_{6}\right.$ and $\left.\mathrm{La}_{0.25} \mathrm{Nd}_{0.75} \mathrm{~B}_{6}\right)$ were extracted in the form of isomeric formations, needles, and plates (Fig. 4), while the lower part was pulled off. Crystals of high-melting $\mathrm{TiB}_{2}$ with various shapes [3] were obtained earlier in the system $\mathrm{Ca}(+\mathrm{B}) / \mathrm{Ce}(+\mathrm{Ti})$ by the same method.

\section{CONCLUSIONS}

The experiments that were carried out indicate the possibility of obtaining various compounds and crystal forms by this method, as well as the existence of various processes in immiscible systems whose analysis presents great interest $[1-3]$. The new method uses the ratio of densities of components in immiscible systems to perform processes of interdiffusion and convection for realization of chemical reactions on the immiscibility boundary and subsequent crystallization of the generated compounds. The method has a number of advantages in comparison with usual solution-melt method.

The interdiffusion and convection promote a fuller contact of reacting components on the immiscibility boundary of melts. This leads to a more complete yield of synthesis. It is possible to save the upper layer metal if one can carve this region (and further extract synthesis products from it) and use the remaining metal for synthesis a second time, under well-proven synthesis conditions of certain compounds which settle in certain regions of the upper layer over the immiscibility boundary.

The new method allows one to obtain various shapes of crystals (isomeric, lamellar, needle), while the solution-melt method obtains crystals of one shape (for example, plates of $\mathrm{TiB}_{2}$ ). It is possible to produce nanoparticles (or particles of size close to them) (for example, needles of $\mathrm{TiB}_{2}$ in system $\mathrm{Ca} / \mathrm{Ce}$ ) under appropriate conditions and initial sizes and shape of reacting particles in certain systems.

The interdiffusion and convection can facilitate production of various solid solutions and also can contribute to production of new compounds from initial reacting components with sharply distinguished densities, since in the usual solution-melt method such components settle above and below the melt and cannot react.

It is necessary to emphasize that synthesis and crystallization of compounds in immiscible systems is a rather new method, which is necessary to research and develop further.

\section{REFERENCES}

1. Burkhardt, U., Boström, M., Schnelle, W., et al., Proc. 9th Conf. in Solid State Chemistry, 2003, Stuttgart, Germany, p. 204. 
2. Burkhardt, U., Gurin, V., and Grin, Yu., Development of the Institute and Scientific Report, MPI CPfS, Dresden, 2006, p. 246.

3. Gurin, V., Burkhardt, U., and Grin, Yu., J. Phys. Conf. Ser., 2009, vol. 176, no. 1, p. 012012.

4. Gurin, V.N. and Korsukova, M.M., Prog. Cryst. Growth Charact., 1983, vol. 6, p. 59.

5. Anosov, V.Ya., Ozerova, M.I., and Fialkov, Yu.Ya., Osnovy fiziko-khimicheskogo analiza (Fundamentals of Physico-Chemical Analysis), Moscow: Nauka, 1976, p. 140.
6. Binary Alloy Phase Diagrams (Second Edition), Massalski, T.B., Ed., ASM International, The Mater. Inform. Soc., 1996, vols. 1-3.

7. Diagrammy sostoyaniya dvoinykh metallicheskikh sistem: Spravochnik $v 3$ t. (Phase Diagrams of Binary Metallic Systems: Handbook in 3 vols.), Lyakishev, N.P., Ed., Moscow: Mashinostroenie, 1996.

8. Diagrammy plavkosti solevykh sistem: Spravochnik, Ch. 1-3 (Liquid-Solid Phase Diagrams of Salt Systems: Handbook, Parts 1-3), Moscow: Metallurgiya, 1977-1979. 